\title{
Optimum Design of Square Air-Core Electromagnetic Coil System
}

\author{
${ }^{* 1}$ Aye T. Ajiboye, ${ }^{1}$ Jaye F. Opadiji, ${ }^{1}$ Joshua O. Popoola and ${ }^{2}$ Oladimeji Oniyide \\ ${ }^{* 1}$ Department of Computer Engineering, University of Ilorin, Ilorin, Nigeria \\ ${ }^{2}$ Department of Electrical and Electronics Engineering, University of Ilorin, Ilorin, Nigeria \\ \{ajiboye.at l jopadiji lolusogo | ooniyide\}@unilorin.edu.ng
}

Received: 12-JUN-2021; Reviewed: 17-AUG-2021; Accepted: 02-SEP-2021

http://dx.doi.org/10.46792/fuoyejet.v6i3.662

\begin{abstract}
Designs of electromagnetic (EM) coil have attracted a lot of attention in the research community due to its applications in several areas of human endeavours. However, the optimal selection of coil wire size and current in the design of Square Air-Core Multi-turn Multilayer Electromagnetic Coil (SAMMEC) with significant wire diameter for both safe and cost-effective products has not been given enough research attention. Therefore, the equation for the flux density produced by a rectangular loop of wire was adopted in the modelling of SAMMEC with significant wire diameter. A coil design chart was constructed based on the developed model and design specifications. Both the feasible and non-feasible design regions and the line of optimum magnetic flux density were identified on the constructed chart. The appropriate wire size and current for the coil were both determined from the design-chart. The diameter, length, resistance, copper loss, and weight of the selected wire for the generation of $0.06 \mathrm{~T}$ flux density were found to be $0.00326 \mathrm{~m}, 267.01 \mathrm{~m}, 0.5502 \Omega, 263.87 \mathrm{~W}$, and $19.86 \mathrm{~kg}$ respectively. The selected wire can produce an optimum flux density of $0.066 \mathrm{~T}$ with current of $24 \mathrm{Amp}$ and associated copper loss of $316.92 \mathrm{~W}$.
\end{abstract}

Keywords- Air core, Electromagnetic coil, Magnetic flux density, Multilayer, Multi-turn

\section{INTRODUCTION}

$\mathrm{T}$ The importance of EM coil designs cannot be overemphasized in the fields of physics and engineering as it serves as the basis for the realization of a large number of scientific and industrial systems. Design of EM coils has attracted several attentions in the research community due to its application in many areas of human endeavours such as bio-electromagnetic experiments (Magdaleno-Adame, Olivares-Galvan, Campero-Littlewood, Escarela-Perez, \& Blanco-Brisset, 2010), calibrations of magnetic field meter (IEEE, 1995; Kotter \& Misakian, 1977), ultra-precision machining (Denkena, Dahlmann, \& Krueger, 2016), sensor for vehicle detection (Mocholí-Salcedo, Arroyo-Núñez, Milián-Sánchez, Palomo-Anaya, \& Arroyo-Núñez, 2016; Mocholí-Salcedo, Arroyo-Núñez, Milián-Sánchez, VerdúMartín, \& Arroyo-Núñez, 2016), water treatment (Ajiboye, Yusuf, Yusuf, \& Ogunlela, 2020), magnetic resonance imaging and spectroscopy (Chapman, Doyle, \& Pohost, 1992) and EM actuators (Kumar, Kumar, Srihari, \& Dayakar, 2015) to mention but few.

However, the optimal selection of coil wire size and current in the design of SAMMEC with significant coil wire diameter to yield both safe and cost-effective products has not been given sufficient attention. SAMMEC is the class of electromagnetic coil wound on air core former with rectangular prism shape and of equal length and width. The first layer is the turns of wire which have direct contact with the core former, while the other layers have same number of turns as the first layer, but their turn lengths and widths increase in a consecutive order of winding.

\footnotetext{
${ }^{*}$ Corresponding Author

Section B- ELECTRICAL/COMPUTER ENGINEERING \& COMPUTING SCIENCES Can be cited as:

Ajiboye A.T., Opadiji J.F., Popoola J.O. and Oniyide O. (2021): Optimum Design of Square Air-Core Electromagnetic Coil System, FUOYE Journal of

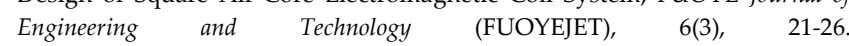
http://dx.doi.org/10.46792/fuoyejet.v6i3.662
}

Merritt and Ruben coils, which are square air-core coils, were among the coil arrangement analysed by (Magdaleno-Adame et al., 2010) for the generation of volumes of uniform magnetic fields. Misakian, $\mathrm{M}$. (Misakian, 2000) developed the equations for the magnetic flux density produced by three rectangular loops of wire lying in the same plane, and the spatial components of the magnetic flux density at any arbitrary point were determined by summing up the respective contributions from each of the loops. In (Misakian, Sheppard, Krause, Frazier, \& Miller, 1993), the equation for the calculation of the resultant magnetic flux density generated at any arbitrary point between two co-axial multi-turn rectangular coils separated by a given distance was derived.

Presented in (IEEE, 1995; Kotter \& Misakian, 1977) are the formulas for calculating the z-component of the magnetic flux density produced by one turn, air-core rectangular coil. The required equation for finding the rms value of the magnetic flux density along the $\mathrm{z}$-axis of a square exposure coil system (ECS) was presented in (Herceg, Juhas, \& Milutinov, 2009) and used to calculate the magnetic flux density of an ECS containing four separate coils. The analytical solution for the calculation of magnetic flux density of double loop air-core rectangular coils was presented in (Mocholí Belenguer, Mocholí Salcedo, Milián Sánchez, \& Arroyo Núñez, 2018) and applied for traffic sensor intelligent transportation system. Applying the principles of superposition, the equation for calculating the magnetic flux density along z-axis produced by square Helmholtz structures (Ghaly \& Khan, 2019) was derived. The analytical determination of the resultant component of the magnetic flux density generated by a square coil at any arbitrary point in the $x$, $y, z$ - surface was presented in (Mocholí-Salcedo, ArroyoNúñez, Milián-Sánchez, Palomo-Anaya, et al., 2016). A method for calculating the magnetic flux density produced by both square and circular air core coils for wireless power transfer systems in electric vehicles was discussed in (Luo \& Wei, 2016). 
Air-core coil arrangements had been traditionally adopted in coil design to guarantee certain spatial distribution of EM fields when fed by an electric current (Azpurua, 2012). High peak amplitude magnetic flux density was produced by an air-core electromagnetic coil, the core also provided a space for accommodating the substance to be magnetically treated (Basharat, Ding, Cai, Li, \& Fang, 2017). The resulting flux density produced by an air-core coil is a linear function of current without saturation which allows easy analysis. As pointed out by (Misakian, 2000), it can be inferred that the square geometry loop is convenient because the expressions for the three spatial components of the flux density are in closed form. For simplification of system model, square coil is encouraged instead of a rectangular coil (Luo \& Wei, 2016). It should be noted that the homogeneity of the magnetic field produced by a pair of square coil system is higher compared to its circular counterpart (Ghaly \& Khan, 2019), as the coil length and width are the same. The design of air-core, square-shaped electromagnetic coil is considered in this study due to the aforementioned advantages associated with this type of coil.

The dependency of the magnetic flux density on coil wire diameter was not analytically established in most of the reported works in the literature; and in a few reports where it was established (Basharat et al., 2017), its investigation was not discussed. This led to the general assumption that all the turns of wire in the coil contribute equally to the resultant magnetic flux density (Azpurua, 2012), however, this is not true for a multi-turn, multilayer coil with significant coil wire diameter. Even though the effect of coil wire diameter on the wire cross-sectional area using the current density was presented in (Azpurua, 2012; Hashemi \& Gharaei, 2019), the effect on the length of the coil wire was not investigated. To address the challenges associated with the design of SAMMEC with significant coil wire diameter, in this study, the coil model was developed and the coil design-chart was constructed using the model and the design specifications. Using the chart, the corresponding values of wire diameter and current can be determined for a specified value of flux density.

\section{Methodology}

In this section, the coil system model equations for the proposed coil system were developed. The developed model equations were used based on the design specifications to design the coil. Also, the wire parameters were determined to provide bases for wire selection.

\subsection{Modelling of Proposed Square CoIl System}

The geometry of a square coil with the length and width of the first layer turn equal to $l_{1}$ and coil height of $h$ is shown in Figure 1. The coil has $n$ layers in the $x-y$ plane and $m$ turns per layer along the z-axis. Based on these layers and turns arrangement with the coil geometry, the formulas for determining the dimensions of a turn in a given layer were derived, as shown in equations (1) - (5) for the first four layers and the $n^{\text {th }}$ layer. The equations for the determination of the distance from the centre of each of the turns in the layers to an arbitrary point $P$ along the $\mathrm{z}$-axis were also derived as shown in equations (6) (10) for the first four turns and $m^{\text {th }}$ turn along the z-axis.

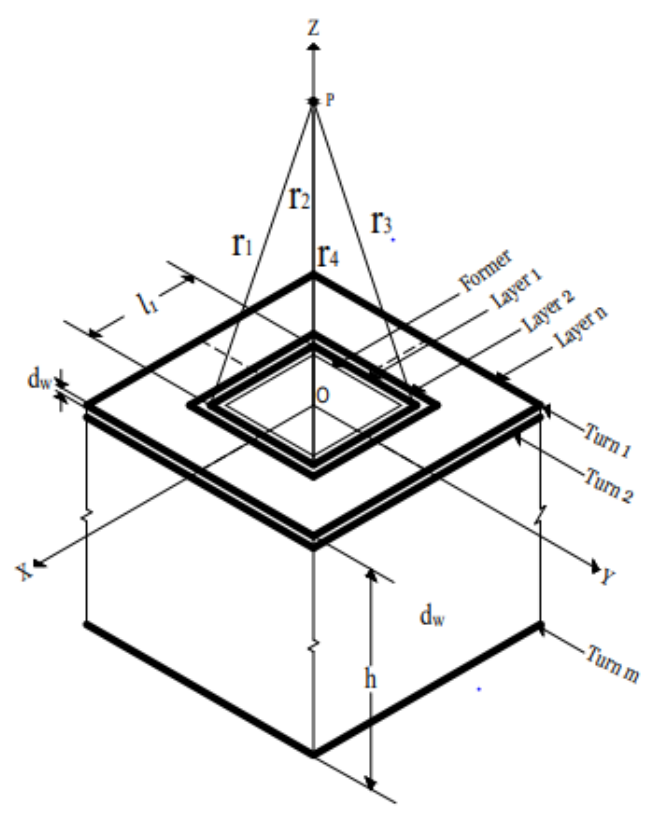

Fig. 1: Geometry of the proposed square coil

$l_{1}=2 a$

$l_{2}=l_{1}+2 d_{w}$

$l_{3}=l_{2}+2 d_{w}$

$l_{4}=l_{3}+2 d_{w}$

$l_{n}=2 a+2(n-1) d_{w}$

where:

$l=$ length/width of the side of a square turn of copper wire along $\mathrm{x}$ - or $\mathrm{y}$-axis in metres

$n=$ index of the coil layers in the $x-y$ plane

$a=$ half of the length of the side of a square turn of copper wire along $\mathrm{x}$ - or $\mathrm{y}$-axis in metres

$d_{w}=$ coil wire diameter in metres

$$
\begin{aligned}
& z_{1}=e \\
& z_{2}=e+d_{w} \\
& z_{3}=e+2 d_{w} \\
& z_{4}=e+3 d_{w} \\
& z_{m}=e+(m-1) d_{w}
\end{aligned}
$$

where:

$e$ is the distance in metres from the center of the first turn in a layer of a square turns on $\mathrm{x}-\mathrm{y}$ plane to point $\mathrm{P}$ along z-axis.

$m=$ index of the square turns in the coil along $z$-axis.

It should be noted that $m$ and $n$ are the number of turns per layer and number of layers, respectively expressed in equations (11) and (12).

$$
\begin{aligned}
& m=\frac{h}{d_{w}} \\
& n=\frac{N}{m}
\end{aligned}
$$

where: $N$ is the number of turns in the coil.

By inspection, from the developed equations by (Misakian, 2000) for calculating the magnetic flux density 
produced by the air-core rectangular loop of wire, the equations for finding the magnetic flux density produced by SAMMEC with significant coil wire diameter was derived. Substituting the general equation for the turn length and the distance from the centre of the turns to point $P$ that is equations (5) and (10) into the equations developed by (Misakian, 2000) yielded the expression for parameters $C_{1, n}$ to $C_{4, n}$ in equations (13) to (16) and that for parameters $d_{1, n}$ to $d_{4, n}$ in equations (17) to (20). These parameters are for all the turns in the coil. Equations (21) to (24) express the wire turns corner distance from point $\mathrm{P}\left(r_{1, n, m}, r_{2, n, m}, r_{3, n, m}\right.$ and $\left.r_{4, n, m}\right)$ as a function of coil physical dimensions, distance from the center of the coil to point $\mathrm{P}$, and coordinate of point $\mathrm{P}$. The $\mathrm{x}-, \mathrm{y}$ - and $\mathrm{z}$-axis components of magnetic flux density as a function of parameters $d, C$, and $\mathrm{r}$; distance from the centre of the coil to point $\mathrm{P}$; the coordinate of point $\mathrm{P}$ and the $C, d$ and $r$ index is as expressed in equations (25) to (27) respectively. And finally, the expression for the resultant flux density $\left(B_{T}\right)$ at point $\mathrm{P}$ as the resultant of the three components is as shown in equation (28).

$$
\begin{aligned}
& C_{1, n}=\frac{l_{n}}{2}+x \\
& C_{4, n}=-\left(\frac{l_{n}}{2}+x\right) \\
& C_{2, n}=\frac{l_{n}}{2}-x \\
& C_{3, n}=-\left(\frac{l_{n}}{2}-x\right) \\
& d_{1, n}=y+\frac{l_{n}}{2} \\
& d_{2, n}=y+\frac{l_{n}}{2} \\
& d_{3, n}=y-\frac{l_{n}}{2} \\
& d_{4, n}=y-\frac{l_{n}}{2} \\
& r_{1, n, m}=\sqrt{\left(\frac{l_{n}}{2}+x\right)^{2}+\left(y+\frac{l_{n}}{2}\right)^{2}+\left(z-z_{m}\right)^{2}} \\
& r_{2, n, m}=\sqrt{\left(\frac{l_{n}}{2}-x\right)^{2}+\left(y+\frac{l_{n}}{2}\right)^{2}+\left(z-z_{m}\right)^{2}} \\
& r_{3, n, m}=\sqrt{\left(\frac{l_{n}}{2}-x\right)^{2}+\left(y-\frac{l_{n}}{2}\right)^{2}+\left(z-z_{m}\right)^{2}} \\
& r_{4, n, m}=\sqrt{\left(\frac{l_{n}}{2}+x\right)^{2}+\left(y-\frac{l_{n}}{2}\right)^{2}+\left(z-z_{m}\right)^{2}}
\end{aligned}
$$

where $r_{1}, r_{2}, r_{3}$ and $r_{4}$ are the distances from the corner of the square turns of wire in the layers to the point $P$.

Note that $n$ and $m$ are as earlier defined and also $C_{1, n}=$ $-C_{4, n} ; C_{2, n}=-C_{3, n} ; d_{1, n}=d_{2, n}$;

and $d_{3, n}=d_{4, n}$.

$B x_{n, m}=\frac{\mu I}{4 \pi}\left(\sum_{i=1, j=1, k=1}^{4, n, m}\left[\frac{(-1)^{i+1}\left(z-z_{k}\right)}{r_{i, j, k}\left[r_{i, j, k}+d_{i, j}\right]}\right]\right)$

where $I$ is the loop current in amperes.

$$
B y_{n, m}=\frac{\mu l}{4 \pi}\left(\sum_{i=1, j=1, k=1}^{4, n, m}\left[\frac{(-1)^{i+1}\left(z-z_{k}\right)}{r_{i, j, k}\left[r_{i, j, k}+(-1)^{i+1} c_{i, j}\right]}\right]\right)
$$

$$
\begin{aligned}
B z_{n, m}= & \frac{\mu I}{4 \pi}\left(\sum _ { i = 1 , j = 1 , k = 1 } ^ { 4 , n , m } \left[\frac{(-1)^{i} d_{i, j}}{r_{i, j, k}\left[r_{i, j, k}+(-1)^{i+1} c_{i, j}\right]}-\right.\right. \\
& \left.\left.\frac{c_{i, j}}{r_{i, j, k}\left[r_{i, j, k}+d_{i, j}\right]}\right]\right)
\end{aligned}
$$

where: $B x, B y$, and $B z$ are the $\mathrm{x}, \mathrm{y}$, and $\mathrm{z}$ components, respectively.

$$
B_{T}=\left(\sum_{i=1, j=1}^{n, m}\left[\left(B x_{i, j}\right)^{2}+\left(B y_{i, j}\right)^{2}+\left(B z_{i, j}\right)^{2}\right]\right)^{1 / 2}
$$

\subsection{CoIL DESIGN}

The coil design specifications for this study, based on Figure 1, are given in Table 1.

Table 1. Coil design specifications

\begin{tabular}{llc}
\hline$S / N$ & Parameters & Value \\
\hline 1. & Required flux density at point $\mathrm{P}$ & $0.06 \mathrm{~T}$ \\
2. & Core height $(\mathrm{h})$ & $4.5 \mathrm{~cm}$ \\
3. & Core length $\left(\mathrm{l}_{1}\right)$ & $7.0 \mathrm{~cm}$ \\
4. & Core width $\left(\mathrm{l}_{1}\right)$ & $7.0 \mathrm{~cm}$ \\
5. & Distance from the center of the first turn & $0.0 \mathrm{~cm}$ \\
& in a layer from point P $(\mathrm{e})$ & \\
6. & Number of copper turns in the coil $(\mathrm{N})$ & 400 \\
\hline
\end{tabular}

The resultant flux density at point $P$ given in equation (28) is a function of the following parameters and variables: $x$, $y, z, e, a, h, \mu_{o}, N, d_{w}$ and $l_{1}$. Point $\mathrm{P}$ is on the z-axis, therefore the value of $x$ and $y$ at point $\mathrm{P}$ will be equal to 0 . Since the value of $e$ is equal to zero, point $P$ will just be at the surface of the coil. The parameters $a$ and $h$ indicated in Figure 1 are the coil core dimensions and are constant once determined. To determine $B_{T}$ in equation (28) any two of $N, d_{w}$ and $I$ can be varied simultaneously after selecting one of them. In this study, the value of $N$ was selected and fixed while the value of $d_{w}$ and $I$ were varied because these two parameters have an established relationship in American Wire Gauge (AWG) standard chart.

Table 2.The extracted values of AWG, wire diameter and wire maximum

\begin{tabular}{lcccccccc}
\hline AWG & $\mathbf{6}$ & $\mathbf{7}$ & $\mathbf{8}$ & $\mathbf{9}$ & $\mathbf{1 0}$ & $\mathbf{1 1}$ & $\mathbf{1 2}$ & $\mathbf{1 3}$ \\
\hline $\mathbf{d x}(\mathbf{m m})$ & 4.11 & 3.67 & 3.26 & 2.91 & 2.59 & 2.3 & 2.05 & 1.83 \\
$\mathbf{I}$ (Amp) & 37 & 30 & 24 & 19 & 15 & 12 & 9.3 & 7.4 \\
\hline
\end{tabular}

\begin{tabular}{lccccccc}
\hline AWG & $\mathbf{1 4}$ & $\mathbf{1 5}$ & $\mathbf{1 6}$ & $\mathbf{1 7}$ & $\mathbf{1 8}$ & $\mathbf{1 9}$ & $\mathbf{2 0}$ \\
\hline $\mathbf{d x}(\mathbf{m m})$ & 1.63 & 1.45 & 1.29 & 1.15 & 1.02 & 0.91 & 0.81 \\
I (Amp) & 5.9 & 4.7 & 3.7 & 2.9 & 2.3 & 1.8 & 1.5 \\
\hline
\end{tabular}

The diameter and maximum current-carrying capacity of the wire are related to AWG (Solaris-shop). Based on this relationship, the AWG value, corresponding wire diameter, and the maximum current value for the wires considered for the coil design in this study were extracted and presented in Table 2.

The relationship between the maximum wire current and wire diameter is shown in Figure 2, and it was used to generate equation (29) which relates the maximum current and wire diameter, by curve fitting the plots of Figure 2. 


$$
I=2.1 \times 10^{6} \times d_{w}{ }^{2}+5.7 \times 10^{2} \times d_{w}-0.5
$$

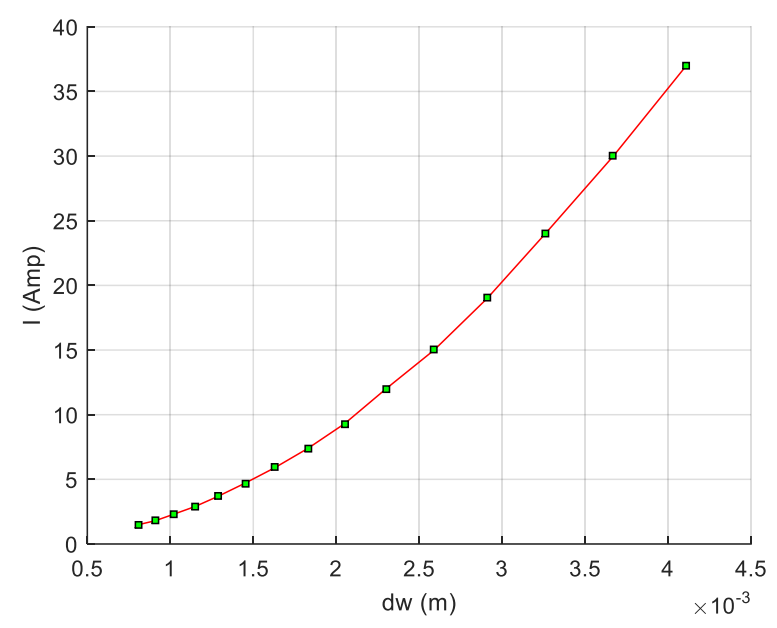

Fig. 2: Plot of wire maximum current against diameter

Using equation (28), the resultant flux density was plotted against the current for a given wire diameter for each of the possible wire sizes considered to construct the coildesign chart, as shown in Figure 3.

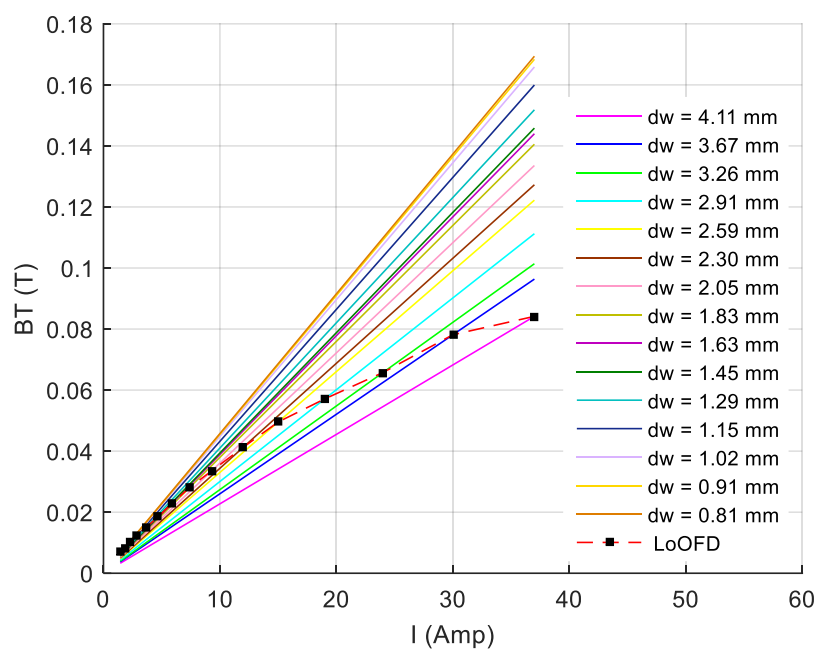

Fig. 3: The extracted coil-design chart

The range of current used for the plot is from the maximum current-carrying capacity of the wire with the smallest diameter to the maximum current-carrying capacity of the wire with the largest diameter. Also, by using the maximum current that can be carried by each of the wire sizes and equation (28) on the same axes of Figure 3, the maximum flux density that can be produced by the current in each of the wires was plotted against the current and is as shown with dash-dash line. This is a line of optimum flux density (LoOFD), as the peak flux density for each of the wires is obtained at the point of its intersection with that of the plot of flux density against current for a given wire diameter. The points of optimum flux density for each of the wires considered are also shown in black square spot in Figure 3.

\subsection{Determination of Wire Parameters}

The technical and economic factors are the two major factors to be considered in magnetic wire selection in the construction of electromagnets. These factors depend on electrical and physical parameters of magnetic wire as contained in the magnetic wire chart (Inc., 1996; Solarisshop). The parameters considered in this study include the maximum current the wire can withstand, wire's resistance, and weight.

These electrical and physical parameters are functions of wire length because their values are normally given in "per kilometer" of the length of each of the wire. Therefore, the parameters are determined by firstly deriving the formula for calculating the length of the wire. The sectional view of the coil shown in Figure 1 is presented in Figure 4, illustrating the coil layers with the length and width of the first layer $\left(l_{1}\right)$, length and width of the $n^{\text {th }}$ layer, wire diameter $\left(d_{w}\right)$ and coil height $(h)$.

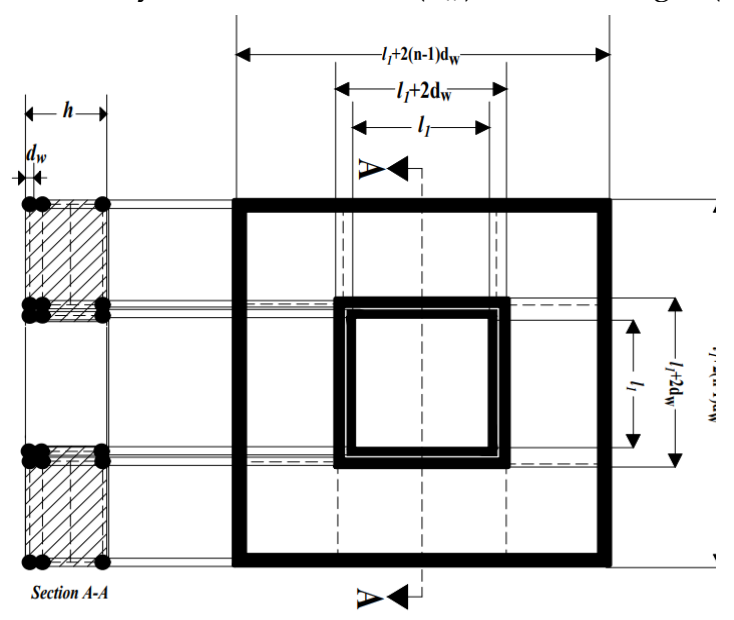

Fig. 4: Sectional view of the square coil

Considering Figure 4 , the perimeters of a wire turn in the $1^{\text {st }}, 2^{\text {nd }}, 3^{\text {rd }}, 4^{\text {th }},(\mathrm{n}-1)^{\text {th }}$ and $\mathrm{n}^{\text {th }}$ layers in the $\mathrm{x}-\mathrm{y}$ plane are expressed in equations (30), (31), (32), (33), (34), and (35), respectively.

$\mathrm{P}_{0}=8 \mathrm{a}$

$\mathrm{P}_{1}=8 \mathrm{a}+4 \mathrm{~d}_{\mathrm{w}}$

$\mathrm{P}_{2}=8 \mathrm{a}+12 \mathrm{~d}_{\mathrm{w}}$

$P_{3}=8 a+20 d_{w}$

$P_{n-1}=8 a+4 d_{w}+(n-2) 8 d_{w}$

$P_{n}=8 a+4 d_{w}+(n-1) 8 d_{w}$

It can be seen that equations (31) - (35) follows arithmetic progression pattern with $P_{1}$ as the first term, $8 d_{w}$ as the common difference, $n$ as the number of terms and $P_{n}$ as the last term. Therefore, the total length of wire in the entire layer with one turn per layer $\left(\mathrm{L}_{\mathrm{T}}\right)$ and for the entire layers and turns $\left(\mathrm{L}_{\mathrm{ET}}\right)$ is as expressed in equations (36) and (37) respectively.

$L_{T}=P_{0}+\frac{n}{2}\left(16 a+8 n d_{w}\right)$

$L_{E T}=m\left[P_{0}^{2}+\frac{n}{2}\left(16 a+8 n d_{w}\right)\right]$

The expression for the resistance of the wire $\left(\mathrm{R}_{\mathrm{w}}\right)$, wire copper loss $\left(\mathrm{P}_{\mathrm{w}}\right)$ and the weight of the wire $\left(\mathrm{W}_{\mathrm{w}}\right)$ is as expressed in equations (38), (39), and (40) respectively.

$$
\begin{aligned}
& R_{w}=\frac{L_{E T} \times R_{p k m}}{1000} \\
& P_{w}=I^{2} R_{w} \\
& W_{w}=\frac{L_{E T} \times W_{p k m}}{1000}
\end{aligned}
$$


where,

$R_{p k m}=$ wire resistance $0 \mathrm{hms}$ per $\mathrm{km}$

$W_{p k m}=$ wire weight in $\mathrm{kg}$ per $\mathrm{km}$

\section{Results ANd Discussions}

As can be seen from Figure 2, the relationship between the maximum current a wire can carry and its diameter is non-linear, as revealed by equation (29) obtained by curve fitting the graph of Figure 2 is quadratic. The corresponding value of current for any given value of wire diameter or vice versa can be obtained from Figure 2 or through a calculation using equation (29).

It can be seen from Figure 3 that for a given value of current the value of flux density increases with a decrease in the value of wire diameter. This is due to the reduction in the distance of point $P$ from the centre of the coil turns (Refer to Figure 1). Because the distance of point $P$ from the centre of any of the coil turns is directly related to the wire diameter as can be seen in equation (10). The point of intersection of the LoOFD with the line of plot of magnetic flux density against the current for a given value of wire diameter gives the value of wire optimum flux density. Any point in the area above the LoOFD in Figure 3 is forbidding for the design because the wire material cannot withstand the resulting heat generated due to copper loss as the value of current in this area is higher than the permissible value for a given wire diameter. But any point below it is safe, it should be noted that the point may not be the optimum point for the wire diameter considered as the optimum points are along the LoOFD.

The coil-design chart of Figure 3 can be used for either optimal or cost-effective design of any size of air-core square electromagnet coil. It can be inferred from Figure 3 that if the wire production technology can be improved to reduce the wire resistance per unit length, the LoOFD will move up and the optimum magnetic flux density for each of the wire will be improved. If the wire resistance can be reduced to $0 \Omega$ the imposition of the limit due to copper loss will not be necessary, the only factor that will then determine the value of flux density produced by any turn of wire will be the distance between point $P$ and the centre of the turns of wire in the coil. Under this condition, the LoOFD will become vertical passing through the point of highest current (in this study $37 \mathrm{~A}$ ) and connect all the lines generated by the plot of flux density versus current for each of the wire diameters. Then the optimum flux density will be achieved at the highest current for each of the wire diameters.

If this condition can be achieved the wire with the smallest diameter will produce the highest flux density for a given value of current while that with the largest diameter will produce the lowest flux density and the best to be selected as applied to this study will be the wire with a diameter of $0.81 \mathrm{~mm}$ which will produce a flux density of $0.06 \mathrm{~T}$ with current of $13.1 \mathrm{~A}$. Since the desired flux density is $0.06 \mathrm{~T}$ and the wire resistance is finite, the appropriate wire size can be determined using Figure 3, and it can be seen from the figure that only 3 wires with diameter $4.11 \mathrm{~mm}, 3.67 \mathrm{~mm}$, and $3.26 \mathrm{~mm}$ out of the 15 wires present on this graph can produce this value of flux density without the current exceeding the wire limit. Each of these wires size will produce this flux with a different value of current $(26.4 \mathrm{~A}, 23.1 \mathrm{~A}$, and $21.9 \mathrm{~A}$ for $4.11 \mathrm{~mm}$, $3.67 \mathrm{~mm}$, and $3.26 \mathrm{~mm}$ diameters, respectively). To select one out of the 3 wires their copper losses and weight which determine the technical and economic factors respectively were compared to create room for selection justification. The wire length, resistance, copper loss, and weight for each of the 3 wires, was obtained using equations (37), (38), (39), and (40) respectively, and is presented in Table 3.

Table 3. Parameters of the potential coil wires

\begin{tabular}{llllll}
\hline $\begin{array}{l}\text { Wire } \\
\text { diameter } \\
(\mathbf{m})\end{array}$ & $\begin{array}{l}\text { Current } \\
(\mathbf{A})\end{array}$ & $\begin{array}{l}\text { Length } \\
(\mathbf{m})\end{array}$ & $\begin{array}{l}\text { Resistance } \\
(\mathbf{O h m})\end{array}$ & $\begin{array}{l}\text { Copper } \\
\text { loss (W) }\end{array}$ & $\begin{array}{l}\text { Weight } \\
(\mathrm{kg})\end{array}$ \\
\hline $\mathbf{0 . 0 0 4 1 1}$ & 26.4 & 355.31 & 0.4604 & 320.91 & 42.00 \\
$\mathbf{0 . 0 0 3 6 7}$ & 23.1 & 307.00 & 0.5017 & 267.69 & 28.79 \\
$\mathbf{0 . 0 0 3 2 6}$ & 21.9 & 267.01 & 0.5502 & 263.87 & 19.86 \\
\hline
\end{tabular}

Based on the design specifications in Table 1 and the value of wire parameters presented in Table 3 , the optimal wire is that with $0.00326 \mathrm{~m}$ diameter because it has the lowest copper loss and weight followed by $0.00367 \mathrm{~m}$ diameter and the least suitable is the $0.00411 \mathrm{~m}$ diameter.

\section{ConCLUSION}

The model equations for the design of SAMMEC with significant wire diameter were developed. The relationship between the current and the wire diameter as contained in the AWG chart was both graphically and mathematically established. The graphical method for the design of SAMMEC with significant wire diameter was developed and the optimum flux density for each gauge of the magnetic wire considered in this study was established.

Furthermore, the equations for determination of the coil wire length and the parameters were also developed. The range of possible wire size for the design specifications and the corresponding value of current was determined from the coil-design chart. Based on the design specifications given in this study the diameter, length, resistance, copper loss, and weight of the selected wire were found to be $0.00326 \mathrm{~m}, 267.01 \mathrm{~m}, 0.5502 \Omega, 263.87 \mathrm{~W}$, and $19.86 \mathrm{~kg}$ respectively. The optimum magnetic flux density that can be produced by the selected wire is 0.066 $\mathrm{T}$, while the corresponding current and copper losses are $24 \mathrm{~A}$ and $316.92 \mathrm{~W}$, respectively.

In future work, finite element method is being proposed for the study of field distribution across the entire geometry of the coil rather than at a single point.

\section{REFERENCES}

Ajiboye, A. T., Yusuf, A. O., Yusuf, K. O., \& Ogunlela, A. O. (2020). Development of Electromagnet for Laboratory Water Treatment Experiments. FUOYE Journal of Engineering and Technology, 5(1). Azpurua, M. A. (2012). A semi-analytical method for the design of coil-systems for homogeneous magnetostatic field generation. 
Progress in Electromagnetics Research, 37, 171-189.

Basharat, M., Ding, M., Cai, H., Li, Y., \& Fang, J. (2017). Design and Analysis of Multilayer Solenoid Coil for Faraday Modulator. Paper presented at the MATEC Web of Conferences.

Chapman, B., Doyle, M., \& Pohost, G. (1992). Optimized electromagnetic coil design theory. Paper presented at the Proceedings IEEE Southeastcon' 92.

Denkena, B., Dahlmann, D., \& Krueger, R. (2016). Design and optimisation of an electromagnetic linear guide for ultraprecision high performance cutting. Procedia CIRP, 46, 147-150.

Ghaly, S. M. A., \& Khan, M. O. (2019). Design, simulation, modeling, and implementation of a square helmholtz coil in contrast with a circular coil for MRI applications. Engineering, Technology \& Applied Science Research, 9(6), 4990-4995.

Hashemi, A., \& Gharaei, P. Y. (2019). A Novel Method for Field Analysis and Design of Electromagnet Used in Lifting Applications. Advanced Electromagnetics, 8(4), 32-38.

Herceg, D., Juhas, A., \& Milutinov, M. (2009). A design of a four square coil system for a biomagnetic experiment. Facta universitatis-series: Electronics and Energetics, 22(3), 285-292.

IEEE. (1995). IEEE Standard Procedures for Measurement of Power Frequency Electric and Magnetic Fields From AC Power Lines (pp. 0-1): IEEE Std 644-1994.

Inc, A. M. W. (1996). Magnet Wire General Engineering Data Bare and Film Insulated Copper and Aluminium.

Kotter, F. R., \& Misakian, M. (1977). AC transmission line field measurements: National Bureau of Standards, Washington, DC (USA). Inst. for Basic Standards.

Kumar, P., Kumar, M. S., Srihari, M., \& Dayakar, K. (2015). Design of magnetic actuator. International Journal of Research in Engineering and Technology, 4(10), 370-374.

Luo, Z., \& Wei, X. (2016). Mutual inductance analysis of planar coils with misalignment for wireless power transfer systems in electric vehicle. Paper presented at the 2016 IEEE Vehicle Power and Propulsion Conference (VPPC).

Magdaleno-Adame, S., Olivares-Galvan, J., Campero-Littlewood, E., Escarela-Perez, R., \& Blanco-Brisset, E. (2010). Coil systems to generate uniform magnetic field volumes. Paper presented at the Excerpt from the proceedings of the COMSOL conference.

Misakian, M. (2000). Equations for the magnetic field produced by one or more rectangular loops of wire in the same plane. Journal of research of the National Institute of Standards and Technology, 105(4), 557.

Misakian, M., Sheppard, A. R., Krause, D., Frazier, M. E., \& Miller, D. L. (1993). Biological, physical, and electrical parameters for in vitro studies with ELF magnetic and electric fields: a primer. Bioelectromagnetics, 14(S2), 1-73.

Mocholí-Salcedo, A., Arroyo-Núñez, J. H., Milián-Sánchez, V. M., Palomo-Anaya, M. J., \& Arroyo-Núñez, A. (2016). Magnetic field generated by the loops used in traffic control systems. IEEE Transactions On Intelligent Transportation Systems, 18(8), 21262136.

Mocholí-Salcedo, A., Arroyo-Núñez, J. H., Milián-Sánchez, V. M., Verdú-Martín, G. J., \& Arroyo-Núñez, A. (2016). Traffic control magnetic loops electric characteristics variation due to the passage of vehicles over them. IEEE Transactions On Intelligent Transportation Systems, 18(6), 1540-1548.

Mocholí Belenguer, F., Mocholí Salcedo, A., Milián Sánchez, V., \& Arroyo Núñez, J. H. (2018). Double magnetic loop and methods for calculating its inductance. Journal of Advanced Transportation, 2018.
Solaris-shop.com (2021). The American Wire Gauge Conductor Size Table. https://www.solaris-shop.com/content/American Wire Gauge Conductor Size Table.pdf. Retrieved June 2021 